\title{
Spinal Arteriovenous Malformations
}

\author{
Antonio López González, Mardjono Tjahjadi, \\ Andrés Muñoz Nuñez, \\ and Francisco Javier Márquez Rivas
}

\subsection{Sign and Symptoms}

Clinical signs and symptoms of spinal arteriovenous malformation (AVM) have different characteristics according to the type of the AVM. Various classifications have been proposed for this complex lesion [1-3]; we use our own modified classification just to simplify our work-up discussion.
We divide the spinal arteriovenous (AV) malformations by their fistula or nidus locations into dural, perimedullary, and intramedullary type and by fistulas or true malformations. Authors identify the dural AV fistulas (dAVF) (Fig. 28.1), perimedullary AV fistulas (AVF) (Fig. 28.2), and spinal cord true AV malformation (AVM) that is either juvenile-type AVM or glomus-type AVM.

\begin{tabular}{|c|c|c|c|c|}
\hline & dAVF [4] & Perimedullary [5] & Juvenile [6] & Glomus [7] \\
\hline Feeder & Radiculomeningeal & Spinal artery & Multiple spinal arteries & Multiple spinal arteries \\
\hline Nidus & $\begin{array}{l}\text { Small, in the dura, close to } \\
\text { nerve root }\end{array}$ & Direct shunt & $\begin{array}{l}\text { Large; not well } \\
\text { delineated; located inside } \\
\text { the spinal cord within } \\
\text { functional neural tissue }\end{array}$ & $\begin{array}{l}\text { Well delineated; located at } \\
\text { one single spinal cord } \\
\text { segment without neural } \\
\text { tissue inside }\end{array}$ \\
\hline Drainage & $\begin{array}{l}\text { Single radicular vein and } \\
\text { then to perimedullary } \\
\text { venous plexus }\end{array}$ & $\begin{array}{l}\text { Perimedullary } \\
\text { venous plexus }\end{array}$ & Giant venous ectasia & $\begin{array}{l}\text { Veins draining to the } \\
\text { perimedullary plexus } \\
\text { can be identified }\end{array}$ \\
\hline
\end{tabular}

\footnotetext{
A. L. González · A. M. Nuñez · F. J. M. Rivas $(\bowtie)$ Department of Neurosurgery, Virgen Macarena and Virgen del Rocío University Hospitals, Seville, Spain e-mail: andresmunioz@hormail.com; jaca5@arrakis.es

M. Tjahjadi

Department of Neurosurgery, Helsinki University

Central Hospital, Helsinki, Finland
} 


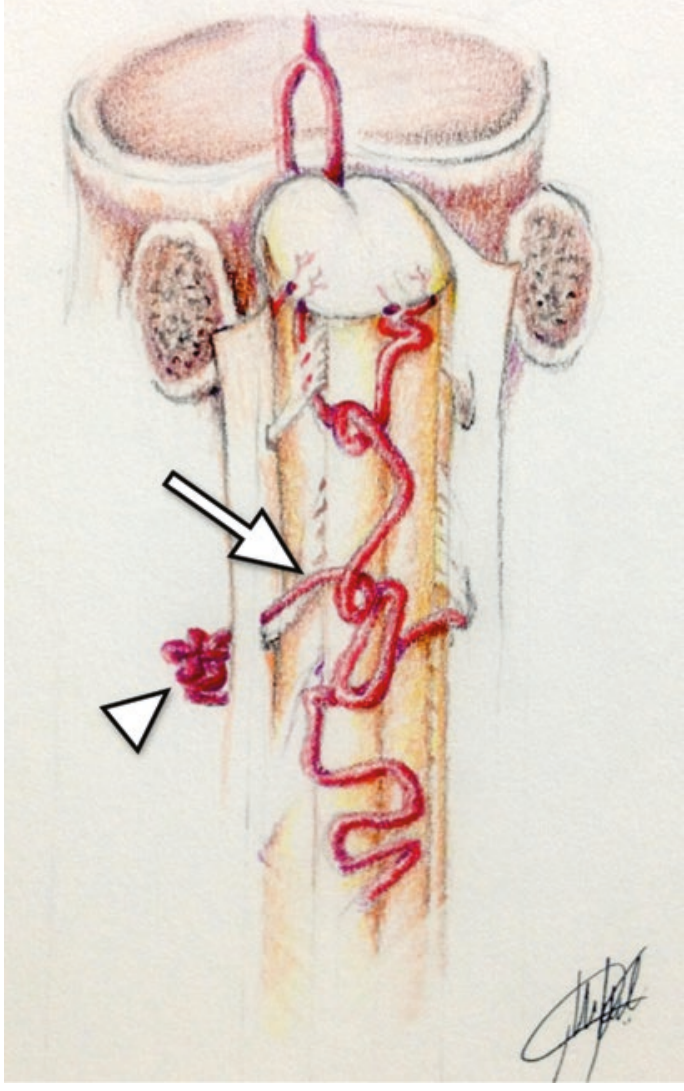

Fig. 28.1 Drawing showing a dAVF. Arrow indicates the fistulous vessel and the arrowhead the dural nidus over the nerve root

Most of the spinal AV malformations are found at the level of lower thoracic and thoracolumbar spine, and dural type is the most commonly found spinal AV malformation.

Patients who have dural type usually come to our service with complaint of slowly progressive myelopathy, and many of them had a long history of intermittent myelopathy previously. The myelopathy is caused by either direct mechanical compression of the spinal cord by the engorging vein or by the disturbance of spinal blood flow that resulted in spinal cord ischemia. In the clinical presentation, motor weakness is the most common symptom, followed by paresthesia and sphincter disturbances. Pain and acute onset of myelopathy are relatively seldom for this spinal AV malformation type. Perimedullary and intra-

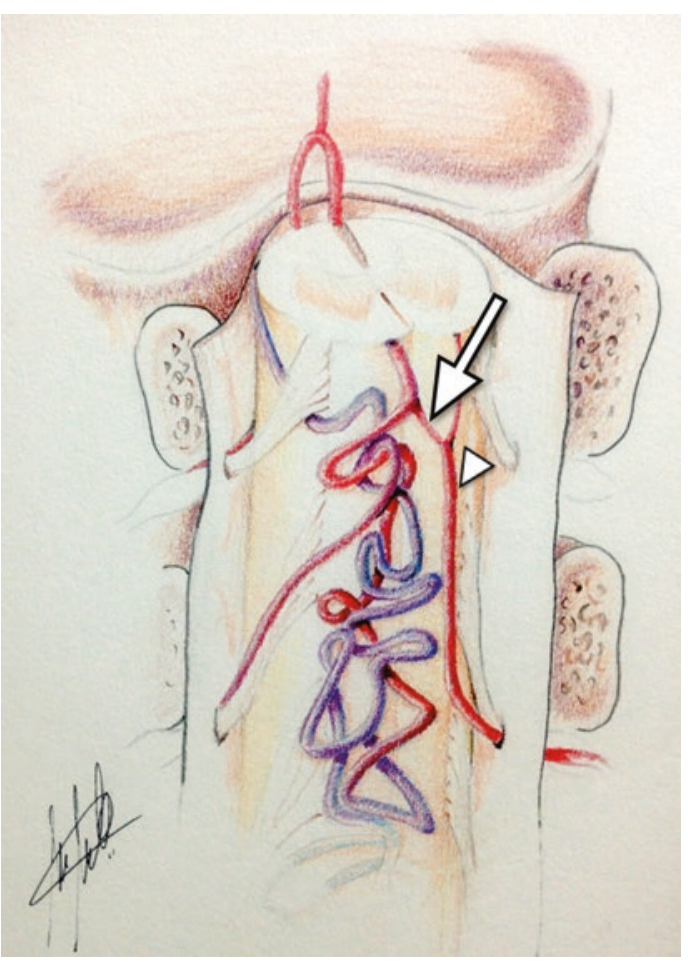

Fig. 28.2 Drawing showing a perimedullary AVF. Arrow indicates the fistulous vessel between a spinal artery and the venous plexus (arrowhead)

medullary type may present as an acute onset of back pain or myelopathy. The pathogenesis is believed to be the ruptured of the nidus that caused subarachnoid hemorrhage or even intramedullary hemorrhage. Meningeal irritation signs might be found in the clinical presentation. But in a low-flow fistula or malformation, the symptoms can develop slowly and give a similar pathogenesis and clinical characteristic to the dural type $[8,9]$.

\subsection{Investigation [4, 10-12]}

Most of the spinal AV malformations are discovered by an MRI/MRA. But it is the selective DSA (digital subtraction angiography) that remains gold standard to identify the number, morphology, exact location, and dynamics of the feeders, nidus, and drainages of the malformation. 


\subsubsection{Magnetic Resonance Imaging}

The T2WI MRI of the spinal cord may show diffuse hyperintense signal at the central area representing edema of the spinal cord. This lesion is possibly accompanied by the hypointense signal that occurs more likely at dorsal surface of the cord. These hypointense signals represent the congested perimedullary venous plexus (Fig. 28.3).

On T1-weighted images, the hypointense and swollen spinal cord is a common finding. Infusion of the contrast agent may show diffuse enhancement represents the chronic congested veins with a breakdown of a spinal cord-blood barrier.

MRA may provide benefit if it could show the suspicious level of the fistula associated with the vertebral level, and then this information can accelerate the selective DSA study.

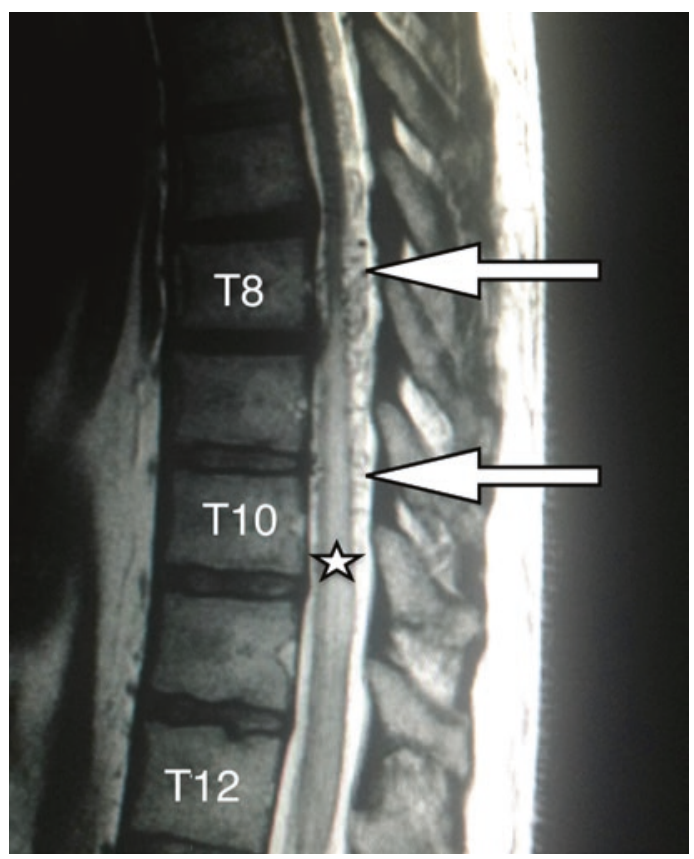

Fig. 28.3 Spine T2-weighted MRI. Sagittal view. Arrows point at hypointense signal areas at the dorsal surface of the cord. These hypointense signals represent the congested perimedullary venous plexus. The star is placed in a diffuse hyperintense signal at the central area of the spinal cord representing edema and radiological myelopathy

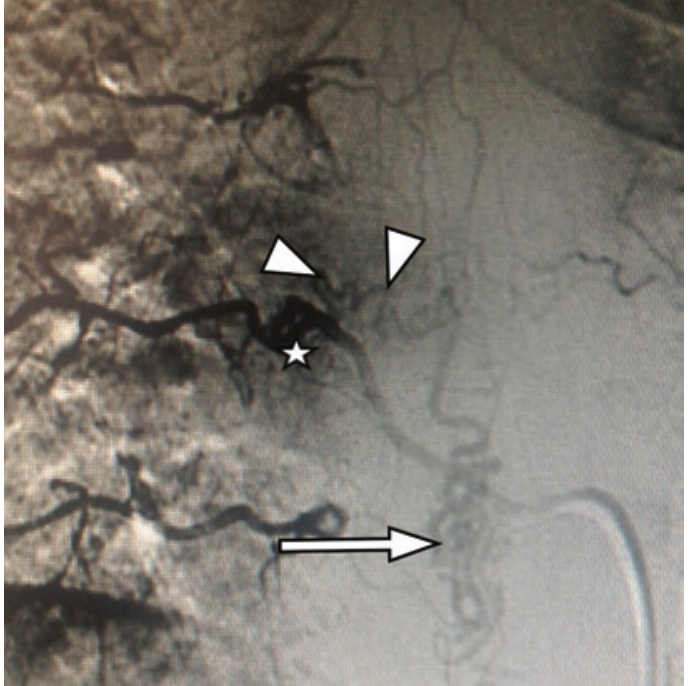

Fig. 28.4 Anteroposterior view of DSA showing a dAVF. The shunt vessel is marked by arrowheads and the engorged venous plexus by the arrow. A star is placed close to the dural nidus

\subsubsection{Digital Subtraction Angiography}

DSA becomes the treatment of choice because of the feasibility of this technique to study in the angioarchitecture of the vessels within or surrounding the lesion. Moreover DSA also gives valuable information about the flow dynamic of the lesions; therefore it can be an important instrument for selection of the treatment modalities (Fig. 28.4).

\subsection{Preoperative Preparation}

The patient must be preoperatively evaluated in a similar way to any other neurosurgical procedures. As surgery for this case is an elective procedure, the patient's general condition should be optimalized. The biochemical analysis and blood and coagulation studies must be evaluated and corrected if necessary prior to the surgery. Two blood bags must be reserved according to the patient's blood group. Any antiplatelet or anticoagulant drug must be stopped, and its effects must be reversed. 
Intraoperative neurophysiological monitoring is not necessary in most of the cases, and it is reserved only for cavernomas and intramedullary AVMs.

Assessment of the exact location of the malformation is crucial for the successful procedure. Careful evaluation of MRI or DSA images is mandatory to know the exact level of the lesion. Marking the location of the skin incision in some situations can be tricky, especially when the lesion is located at the middle level of the back. Utilization of preoperative fluoroscopy is recommended to make a proper skin incision marking. The lateral fluoroscopy view is used by identifying the L5-S1 space, and the spine level can be counted cranially. The anteroposterior view helps us to identify the last rib and T12. This procedure can be done 1 day or several hours prior to the surgery, and to avoid any inaccuracy marking, we ask an interventional CT radiologist to draw the location of the lesion at the patient's skin and fix it with a single staple.

\subsubsection{Positioning}

Patient is placed in a prone position with over two chest rolls or a Wilson frame. For lesions located at the dorsal spine, the two arms rest over armrests; for lumbar lesions, we prefer the kneechest position and, for cervical spine lesions, the Wilson frame and the head fixed by Mayfield three-pin frame with patient's arms fixed and held parallel to the body (Figs. 28.5 and 28.6).

\subsubsection{Approach}

Spinal cord AVMs need a bilateral laminectomy, laminoplasty, or unilateral laminectomy to reach the lesion.

Skin incision marking is made longitudinally in the midline, over the spinous process long enough to get a good exposure of the spinal laminas below which the vascular lesion is. The site of skin incision is infiltrated with a mixture of ropivacaine and lidocaine combined with adrenaline. Skin incision is made with a scalpel no. 21;
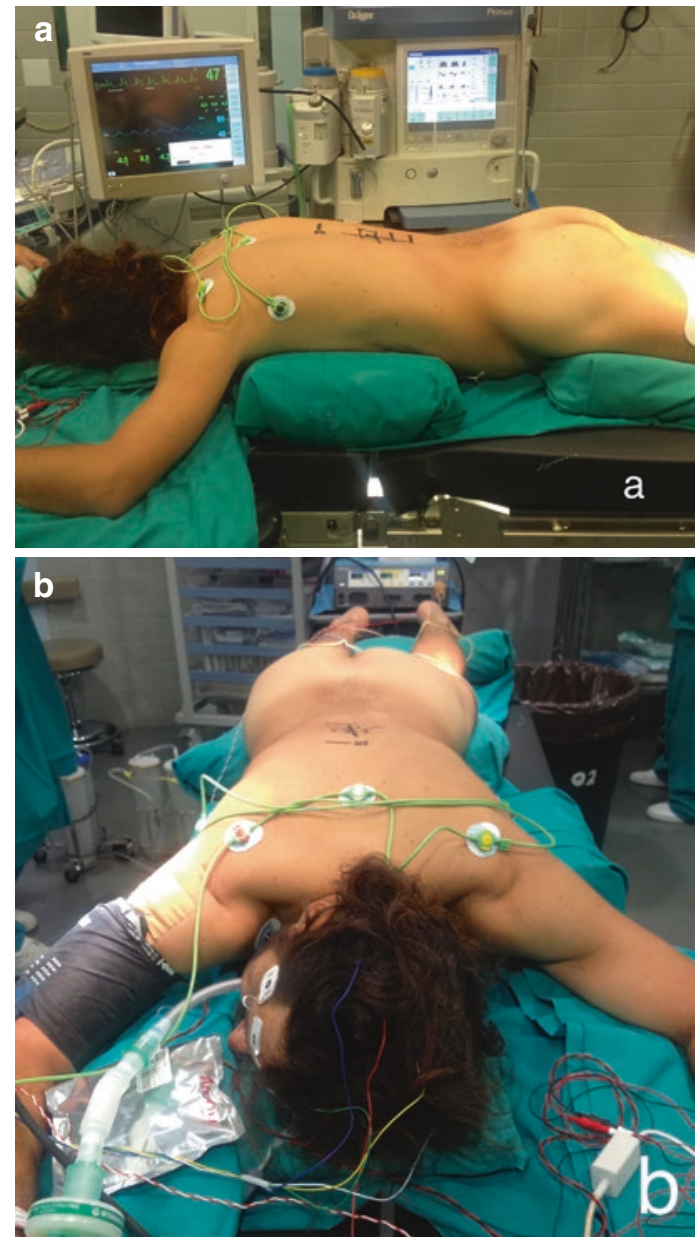

Fig. 28.5 (a) Lateral view of intraoperative patient's position. In this case, the chest and hips are placed over soft supports. The arms are over armrests. The incision has already been marked in the midline. (b) Cranial view. The head is turned right, and electrodes for neurophysiological monitoring are placed in the scalp and legs

the subcutaneous layers are divided through the midline using the monopolar diathermy set at 50 .

If the vascular lesion is a dAVF, we only need to dissect the ipsilateral muscles from the spinous process and laminas. As the target is the root entry, a unilateral laminectomy is enough to reach the field. We can prevent muscle bleeding by doing the dissection just at the plane between the muscle and bone and using bipolar cauterization set at 50 (for Malis bipolar system; Codman, Raynham, MA, USA) when a bleeding vessel is detected. Achieving a good hemostasis will make 


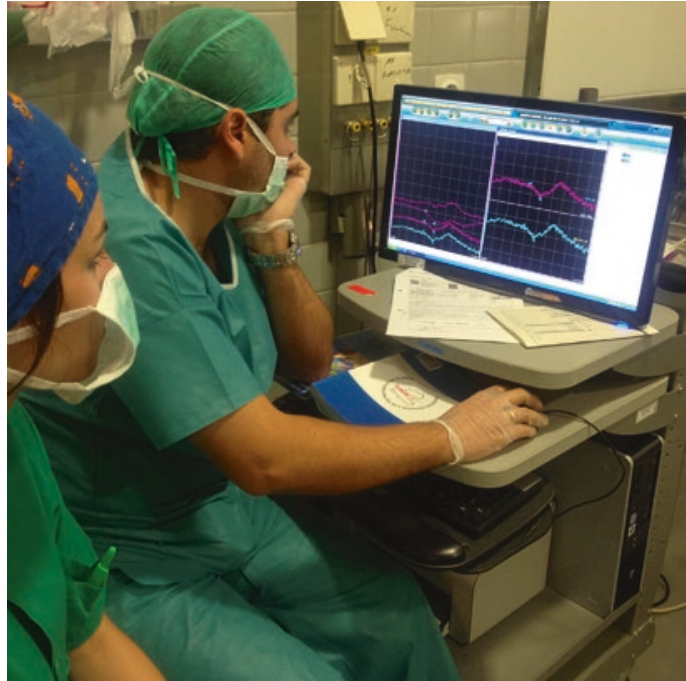

Fig. 28.6 The neurophysiologist is monitoring intraoperatively motor and somatosensory evoked potentials

surgery faster and easier. We may dissect the contralateral laminas partially for the easier placement of the muscle retractor.

It is important to retract the muscle not too tight to prevent the damage of the muscles that result in the postoperative back pain and increase the risk of infections. It is important to retract the muscle not too tight to prevent the muscle ischemia that may produce postoperative back pain and increase the risk of infections. If the lesion is a perimedullary AVF, a cavernoma, or a perimedullary or intramedullary AVM, a bilateral laminectomy, after bilateral muscle dissection, must be performed large enough to expose completely the malformation before the dura opening. For laminectomy, we use Beyer and Kerrison rongeurs.

In younger patients, a laminoplasty is an alternative. The procedure is done using the side-cut drill that is used in craniotomies. The laminas are cut and elevated maintaining the supraspinous and interlaminar ligaments (Fig. 28.7). After the spinal AVM removal, the laminas are placed into its location and fixed with titanium plates and screws.

After bone removal, good hemostasis must be achieved with bone wax over the bleeding bone and hemostatic agents such as Surgicel ${ }^{\circledR}$, Helitene ${ }^{\circledR}$, fibrin glue, or Tachosil ${ }^{\circledR}$ to stop the epidural venous bleeding.

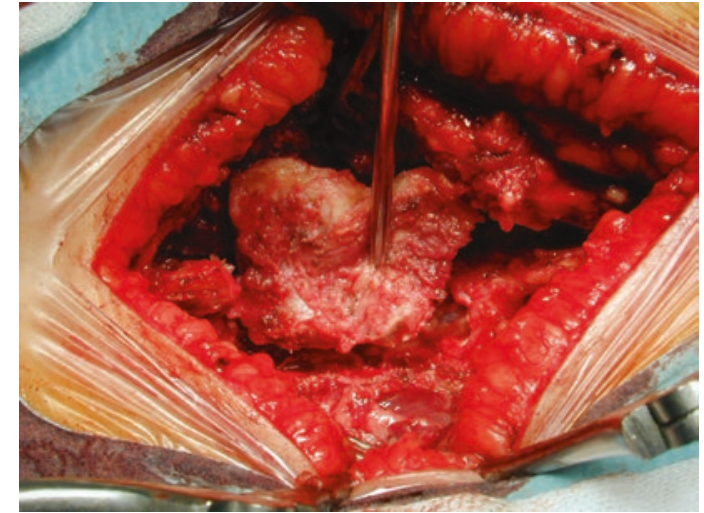

Fig. 28.7 Laminoplasty. The laminas are cut and elevated maintaining the supraspinous and interlaminar ligaments

The use of high-magnification operating microscope, powerful light source, and stereoscopic vision allows the neurosurgeon to use suitable delicate tools to operate on spinal cord lesions in an almost bloodless field. The microscope allows visualization and 3D appreciation of the relevant and detailed neuroanatomical structures [13].

\subsection{Steps of the Surgery}

The dura is necessarily observed carefully prior to the opening of dura, because the dura may firmly adhere to the draining vein or to the AVM itself. Adhesion is even more common in redo cases and prior episode of several bleedings and/ or embolization.

In the midline, we prefer to perform a small cut in the dura with a scalpel blade no. 15. Then, we divide it longitudinally by pulling each dura edges back with two microforceps with teeth. This way of opening the dura minimizes the risk of cutting accidentally any superficial dilated vein with the tip of the sharp blade. The maneuver must be done in the midline for perimedullary AVFs, AVMs, and cavernomas, but if the approach has been performed through an ipsilateral laminectomy, the dura incision is done longitudinally in the middle of the dural area exposed. 
The bilateral dural edges are tacked up by using 4/0 Safil ${ }^{\circledR}$ violet taper-point sutures. The tack-up stitches are used for two purposes: to expose widely the spinal cord and to stop oozing from the epidural space. Fibrin glue and surgical packing further enhance this effect. From this point on, the bipolar power setting is turned down to $20-25$.

\subsubsection{Dural and Perimedullary AV Fistula}

If the patient suffers a spinal dAVF, our aim is to localize the exiting nerve root intradurally because the location of the fistula is expected near to the root.

Sometimes the anatomy is not clear at all at this point, and in order to ensure the correct fistulous vein, we do a small trick using the support of intraoperative video-angiography with indocyanine green (ICG). If the surgical microscope is equipped with infrared camera, after intravenous injection of ICG, the field of interest is illuminated with near-infrared light that shows realtime and dynamic angiographic images. Our trick is to compress the fistulous vein we suspect with a vascular temporary clip and then order the anesthesiologist to inject the indocyanine green of $0.2-0.5 \mathrm{mg} / \mathrm{kg}$. As soon as we see the arterial phase, we release the temporary clip, and if the whole engorged perimedullary venous plexus fills immediately, it confirms that we compressed the feeding vessel of the fistula [14].

At this point, we coagulate the fistulous vein and divide it with microscissors (Fig. 28.8). To clip the fistulous vein with a vascular clip is also possible (Fig. 28.9). It is not necessary to localize the nerve root artery extradurally or remove the dural nidus. A new ICG video-angiography will show no filling or very slow filling of the venous plexus.

In the perimedullary AVFs, sometimes it is difficult to identify the fistula between perimedullary artery and venous plexus because the fistula may be hidden by the engorged venous plexus. In this situation, we must carefully identify the structures with microdissectors and perform an ICG video-angiography. When we have
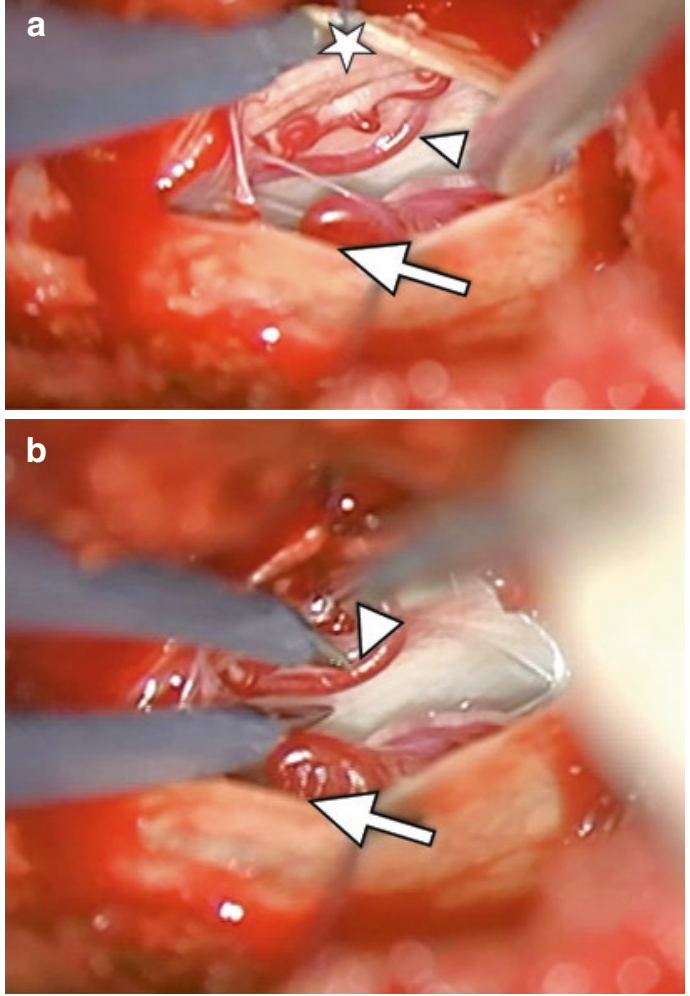

Fig. 28.8 (a) A dAVF under the operating microscope. After the dura is opened, the next structures can be identified: the nerve root (star), the fistulous vessel (arrowhead), and the engorged venous plexus (arrow). (b) The fistulous vessel is coagulated with bipolar forceps set at 20 (for Malis bipolar system; Codman, Raynham, MA, USA) before being cut with microscissors

definitively identified the connection, we perform in the same way that in dAVFs, the vessel is coagulated and cut.

\subsubsection{Glomus AV Malformations}

Only true spinal cord glomus-type AVMs that are located in the posterior horn can be managed surgically. Ventral AVMs or juvenile spinal AVMs at any location are extremely difficult or impossible to remove.

In the glomus-type AVMs, the midline dura opening must be done carefully because the previous subarachnoid hemorrhages at this level may promote adherences between the nidus, arachnoid, and dura mater. 


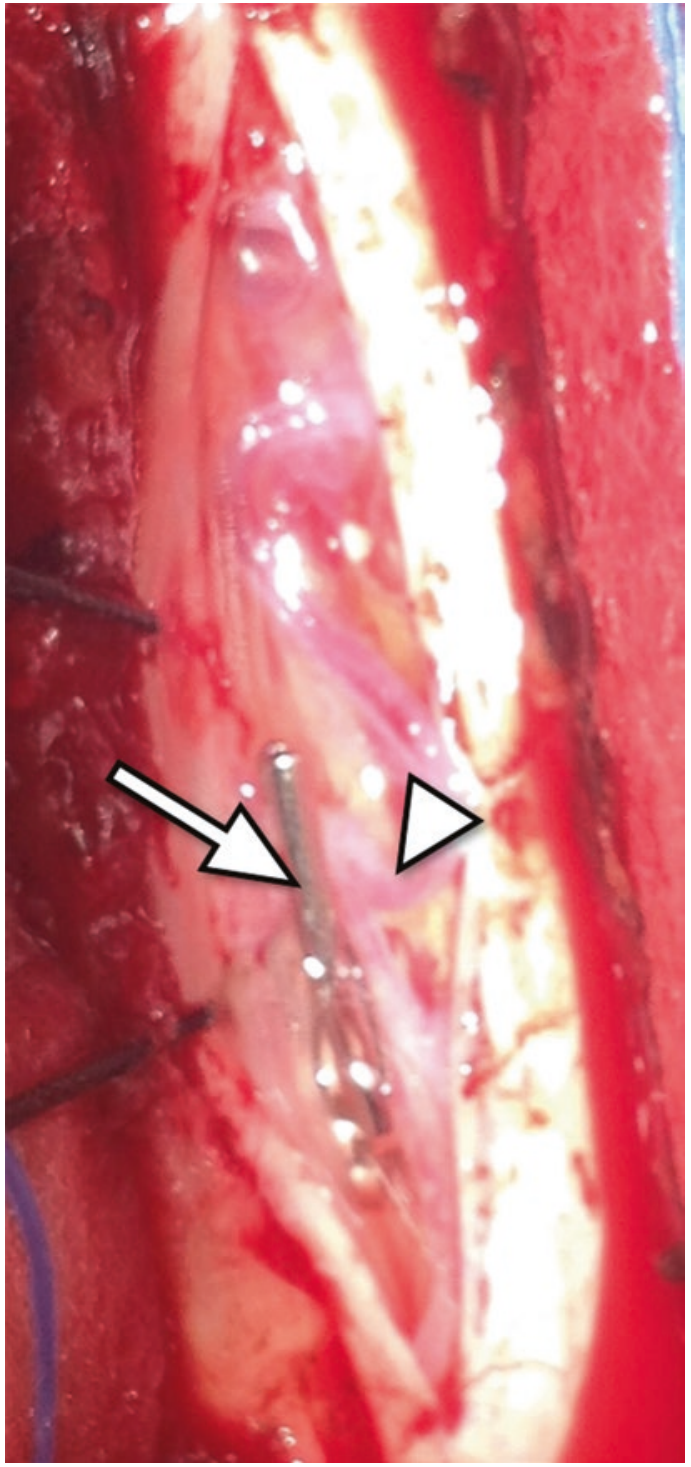

Fig. 28.9 A dAVF case. In this case, the neurosurgeon decided to clip the fistulous vessel with a definitive clip (arrow). After clipping, the venous plexus is less engorged (arrowhead)

After multiple dura tack-up stitches, the posterior horns of the spinal cord and the superficial AVM are exposed, and a diamond micro-knife is used to make pia mater incision at the border of nidus.

The correlation between angiography features of the AVM and the AVM itself in the operation field is extremely important to allow the early finding of the feeders and venous drain- age. If the AVM was previously embolized, the particles inside the vessels can be visualized, and it makes the identification of feeder arteries easier. Normal medullary arteries (especially Adamkiewicz and anterior spinal artery) must be preserved. The dissection of the nidus from the gliotic medullary tissue must be very gentle, and it carries on by using bipolar forceps in the right hand and the suction in the left hand. Bipolar is not only used for cauterization but also as forceps. And the suction tube over a small cottonoid is used as a gentle retractor. The interruption of the feeding arteries is done using the micro-clipping or bipolar coagulation and cutting. When the nidus is totally dissected, bipolar cauterization to shrink the AVM makes its manipulation and final dissection easier. Only prior to the final AVM removal, the drainage veins are coagulated and cut. Abundant irrigation with saline solution and meticulous hemostasis should be achieved.

\subsubsection{Spinal Cord Cavernomas}

Surgical removal is possible for those spinal cord cavernomas which are located posteriorly or close to the midline. The gently opening of the posterior median sulcus allows to reach cavernomas placed in the midline or deep but adjacent to the posterior median sulcus. Fine dissection of the lesion with micro-instruments (in a similar way than for a well-delineated tumor) allows to remove it completely with low risk of bleeding or coagulation of any artery that supplies the spinal cord. It is important to achieve the gross resection because remnants may cause rebleeding and myelopathy.

For all the procedures described, final hemostasis is mandatory followed by waterproof dura closing in order to avoid postoperative linkage which would contribute to a longer postoperative period. To close the dura, we use 4/0 silk taper-point sutures. Epidural hemostasis is also important. We use bone wax for the bone and Surgicel ${ }^{\circledR}$, Tachosil $^{\circledR}$, or fibrin glue for the epidural venous bleeding. If the approach has been made through a laminoplasty, the 


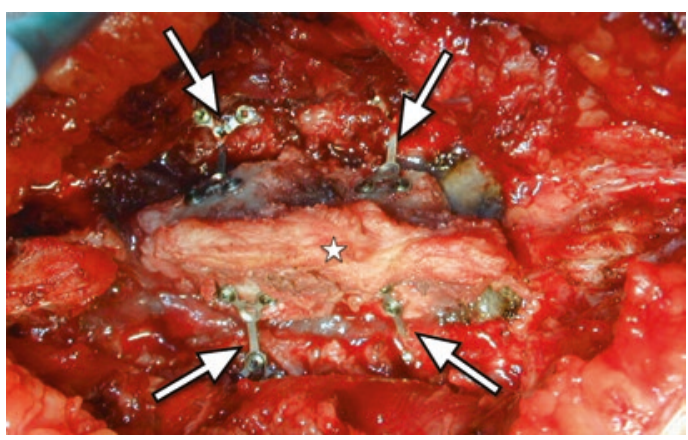

Fig. 28.10 If a laminoplasty is performed, the laminas (star) are placed into its original position and fixed by using miniplates (arrows)

laminas are replaced at this point and fixed with titanium miniplates (Fig. 28.10).

The muscle and fascia are closed with $0 / 0$ Safil ${ }^{\circledR}$ violet cutting-point sutures and, finally, subcutaneous layers with $2 / 0$ sutures.

\subsection{Surgeon Plan to Handle the Complication}

The most common complications after spinal cord surgeries are related to the closing. As it has been mentioned above, dura must be closed carefully in order to prevent CSF linkage. We always use tehsil and/or fibrin glue in order to achieve hemostasis but also to reinforce the dura closing. Laminoplasty itself, and the muscle and fascia properly closed as well, helps to prevent pseudomeningocele formation.

When a postoperative CSF leakage by the wound is detected, we order bed rest, external lumbar CSF drainage for 5 days, and prophylactic treatment with antibiotics. If the leakage still persists, a second surgical procedure is performed to identify the location of the defect and close it with stitches or sealants.

After a successful surgery, patient immediate neurological recovery is not expected. Stability of the symptoms and slow recovery are also signs of good results of the procedure. In some situations, especially in dural or perimedullary arteriovenous fistula cases, there is an increasing risk of perimedullary venous plexus thrombosis after the fistula disconnection. It may cause a temporary postoperative neurological worsening. Bed rest and prophylactic dosages of heparin help to prevent this situation. Prothrombotic effects of steroids can also promote vein thrombosis. Postoperative back pain may occur and analgesic infusion may be needed for 2-3 days. Proper skin incision and muscle dissection will help in reducing the risk of postoperative pain.

Intraoperative neurophysiological monitoring will be helpful in alerting the neurosurgeon of any sensory or motor conduction disturbances during the procedure and gives prognostication of patients' neurological state postoperatively.

A non-expected postoperative patient motor deterioration should be followed immediately by a neurological and radiological exploration. An MRI can distinguish between spinal cord edema, epidural hematoma with compression, and other mechanical reasons that can be treated surgically.

\section{References}

1. Spetzler RF, et al. Modified classification of spinal cord vascular lesions. J Neurosurg. 2002;96(2 Suppl):145-56.

2. Zozulya YP, et al. Spinal arteriovenous malformations: new classification and surgical treatment. Neurosurg Focus. 2006;20(5):E7.

3. Rosenblum B, et al. Spinal arteriovenous malformations: a comparison of dural arteriovenous fistulas and intradural AVM's in 81 patients. J Neurosurg. 1987;67(6):795-802.

4. Krings T, Geibprasert S. Spinal dural arteriovenous fistulas. AJNR Am J Neuroradiol. 2009;30(4):639-48.

5. Djindjian M, Djindjian R, Rey A, et al. Intradural extramedullary spinal arteriovenous malformation fed by the anterior spinal artery. Surg Neurol. 1977;8:85.

6. Berenstein A, Lasjaunia P. Endovascular treatment of spine and spinal cord lesions. Surgical neuroangiography, vol. 4. Heidelberg: Springer; 1992. p. 24-75.

7. Boström A, Krings T, Hans FJ, Schramm J, Thron AK, Gilsbach JM. Spinal glomus-type arteriovenous malformations: microsurgical treatment in 20 cases. J Neurosurg Spine. 2009;10(5):423-9.

8. Dumont AS, Oldfield EH. Spinal vascular malformations. In: Winn HR, editor. Youmans neurological surgery, vol. 4. Philadelphia: Elsevier; 2011. p. 4167-202.

9. Jellema K, et al. Spinal dural arteriovenous fistulas: clinical features in 80 patients. J Neurol Neurosurg Psychiatry. 2003;74(10):1438-40. 
10. Saraf-Lavi E, et al. Detection of spinal dural arteriovenous fistulae with MR imaging and contrast-enhanced MR angiography: sensitivity, specificity, and prediction of vertebral level. AJNR Am J Neuroradiol. 2002;23(5):858-67.

11. Krings $\mathrm{T}$, et al. Imaging in spinal vascular disease. Neuroimaging Clin N Am. 2007;17(1):57-72.

12. Toossi S, et al. Utility of MRI in spinal arteriovenous fistula. Neurology. 2012;79(1):25-30.
13. Lehecka M, Laakso A, Hernesniemi J, Çelik Ö. Helsinki microneurosurgery basics and tricks. 2011. p. 77-8.

14. Simal Julián JA, Miranda Lloret P, López González A, Evangelista Zamora R, Botella Asunción C. Indocyanine green videoangiography in negative: definition and usefulness in spinal dural arteriovenous fistulae. Eur Spine J. 2013;22(Suppl 3):S471-7.

Open Access This chapter is licensed under the terms of the Creative Commons Attribution 4.0 International License (http://creativecommons.org/licenses/by/4.0/), which permits use, sharing, adaptation, distribution and reproduction in any medium or format, as long as you give appropriate credit to the original author(s) and the source, provide a link to the Creative Commons license and indicate if changes were made.

The images or other third party material in this chapter are included in the chapter's Creative Commons license, unless indicated otherwise in a credit line to the material. If material is not included in the chapter's Creative Commons license and your intended use is not permitted by statutory regulation or exceeds the permitted use, you will need to obtain permission directly from the copyright holder.

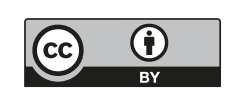

